\title{
Prosthetic valve endocarditis after transcatheter aortic valve replacement: A case report and current review
}

\author{
Tarek Chami ${ }^{1}$, Guilherme Attizzani*2 \\ ${ }^{1}$ Department of Medicine, University Hospitals Cleveland Medical Center; School of Medicine, Case Western Reserve University, \\ Cleveland, $\mathrm{OH}, \mathrm{USA}$ \\ ${ }^{2}$ Harrington Heart and Vascular Institute, University Hospitals Cleveland Medical Center, Cleveland, OH, USA
}

Received: November 30, 2016

Accepted: February 16, $2017 \quad$ Online Published: February 22, 2017

DOI: $10.5430 /$ crim.v4n2p10

URL: https://doi.org/10.5430/crim.v4n2p10

\begin{abstract}
Prosthetic valve endocarditis (PVE) after transcatheter aortic valve replacement (TAVR) is a rare but very serious and often deadly complication. Despite that, data are scarce and limited. Here, we report a case of a patient who developed PVE three months following TAVR and review the literature.
\end{abstract}

Key Words: Endocarditis, Transcatheter valve

\section{INTRODUCTION}

Transcatheter Aortic Valve Replacement (TAVR) has emerged as an effective treatment for severe aortic stenosis in patients with inoperable, high, or intermediate-risk. ${ }^{[1-3]}$ Despite improvement in clinical experience, TAVR is not free of complications. Prosthetic valve endocarditis (PVE) after TAVR is a rare but very serious and often deadly complication. ${ }^{[4]}$ Surgical valve replacement (SVR) remains the cornerstone treatment for complicated PVE. However, the patients undergoing TAVR are often elderly and have complex comorbidities which may eventually preclude or substantially increase the risk of SVR. Herein, we describe a case report of a patient who developed PVE after TAVR three months following the procedure. We will briefly review epidemiology, pathogenesis, and presentation, and then focus on the diagnosis and the management of this complication.

\section{Case description}

A 79-year-old male was admitted to an outside hospital with shoulder pain, shortness of breath, chills, and fever three months after undergoing a TAVR with a $29 \mathrm{~mm}$ XT SAPIEN valve (Edwards Lifesciences, Irvine, CA, USA) via the left femoral artery. His medical history is significant for coronary artery disease status post coronary artery bypass graft, heart failure with preserved ejection fraction (HFpEF), atrial fibrillation, thoracic aortic aneurysm, chronic kidney disease, bladder carcinoma, type II diabetes mellitus controlled with diet, and dyslipidemia. Blood cultures yielded methicillin-resistant staphylococcus epidermidis. Transthoracic echocardiogram (TTE) did not show any vegetation. Transesophageal echocardiogram (TEE) showed a vegetation on the aortic surface of the right coronary cusp (see Figure 1 ), with thickening of the other leaflets of the bioprosthetic valve. There was increase in the perivalvular regurgitation and evidence of a perivalvular abscess (see Figure 2) with a small amount of flow within it. Saline contrast bubble study showed small patent foramen ovale with bidirectional shunting across atrial septum. There was also moderate thickening of the anterior and posterior mitral valve leaflets with moderate mitral valve regurgitation and severe tricuspid valve

\footnotetext{
*Correspondence: Guilherme Attizzani, MD; Email: guilherme.attizzani@uhhospitals.org; Address: Harrington Heart \& Vascular Institute,
} University Hospitals, Cleveland Medical Center, 11100 Euclid Ave, Cleveland, OH 44106, USA. 
regurgitation. There was no recent preceding dental or any other invasive procedures. Antibiotics for IE were started and he underwent emergent redo-sternotomy with removal of the native and bioprosthetic aortic valves, debridement, and patching of the periaortic root abscess. The aortic valve was replaced with a mechanical valve. Postoperative course was complicated with distributive and cardiogenic shock, ventricular tachycardia requiring cardioversion and multi-organ failure. He expired two days after the operation.

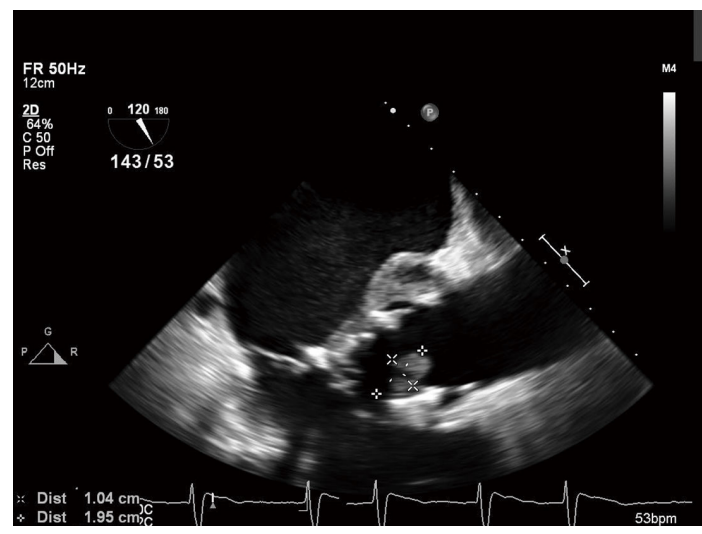

Figure 1. Transesophageal echocardiography (TEE) showing vegetation on the aortic surface of the right coronary cusp

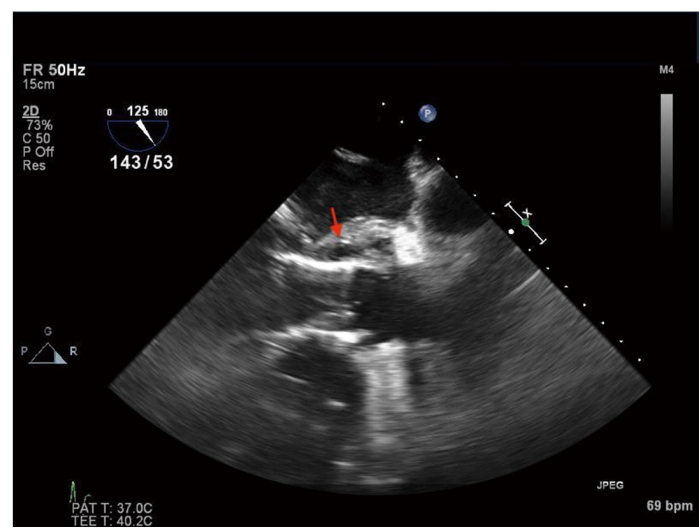

Figure 2. Transesophageal echocardiography (TEE) showing perivalvular abscess

\section{Discussion}

PVE is a very serious infection that may lead to numerous complications. Bioprosthetic valves such as the ones used in TAVR, are a nidus for platelet-fibrin thrombus deposition and subsequent infection. Pathogens enter either via direct contamination during valve placement or through the bloodstream during invasive medical or surgical procedures. The pathogen adheres to the disrupted endothelial lining of the heart through the adhesins proteins. Afterwards, colonization occurs leading to the formation of the vegetation. The

Published by Sciedu Press attachment of these microorganisms cells to cells within the embedded self-produced matrix of extracellular polymeric substance creates a biofilm which allows them to evade the host immune response. ${ }^{[5]}$ Furthermore, the space between the bioprosthesis and the native valve cusp may be a suitable nest for pathogen accumulation during transient bacteremia. PVE after TAVR has been reported in both balloon-expandable (Edwards SAPIEN, Edwards Lifesciences Inc, Irvine, CA) and self-expandable (CoreValve, Medtronic, Minneapolis, $\mathrm{MN})$ valves. The onset ranges from early ( $<60$ days), intermediate (60-365 days), or late ( $>365$ days) with a median of 5 months after TAVR. ${ }^{[6-8]}$ The rate of the infection appears to be higher in the first year after the procedure, likely due to the lack of complete endothelialization of the bioprosthetic valve. ${ }^{[7-9]}$ The incidence of clinical PVE after TAVR spans between $0.6 \%$ and $3 \%,{ }^{[6,8-10]}$ although autopsy studies show a rate closer to $12 \% .{ }^{[4]}$ The median age at diagnosis was 80 years. ${ }^{[8,11]}$ Respiratory infections, and dental and urologic procedures were the leading source for bacteremia, ${ }^{[6,9,10,12]}$ though in half of the patients, the source of infections could not be identified. ${ }^{[6]}$ Several risk factors have been identified; male gender, diabetes mellitus, moderate or severe paravalvular leak (PVL), prior infections, and non-optimal positioning of the transcatheter valve. ${ }^{[6,8-11,13,14]}$ Fever and heart failure were the two most common presenting symptoms. ${ }^{[6,8,9]}$ Reported pathogens include Staphylococcus spp. (aureus, epidermidis, lugdunensis), Streptococcus spp. (anginosus, sanguinis, mitis), Enterococcus spp. (faecalis, faecium), Corynebacterium spp., Granulicatella spp., Pseudomonas spp., Escherichia coli, Bartonella spp., and Moraxella spp., as well as fungi such as Histoplasma capsulatum, Aspergillus fumigatus, and Candida spp. ${ }^{[6,8,9,12,14]}$ Early-onset PVE is most often caused by Staphylococcus, as was seen in our case, signifying a hospital acquired infection. ${ }^{[7,9,10]}$ Most of the data in regard to PVE after TAVR is extrapolated from PVE after SVR. Therefore, there is no clear consensus or guidelines about how to treat or diagnose PVE after TAVR. It is important to note that up to $20 \%$ of blood cultures were negative. However, the presence of positive blood cultures is associated with more virulent pathogens and worse outcomes. ${ }^{[14]}$ Echocardiogram remains the imaging of choice for diagnosing PVE. Findings range from valve vegetation, abscess, fistula, pseudoaneurysm, mitral and aortic regurgitation, rupture of anterior leaflet of the mitral valve, and an increase in the transvalvular gradient. ${ }^{[9,14]}$ Nevertheless, the metal struts encircling the valve leaflets could obscure these findings. ${ }^{[14]}$ Vegetations exist in $70 \%$ and most are located on the leaflets, followed by the stent frame and the mitral valve. ${ }^{[6,8,9]}$ Cardiac computed tomography (CCT) and positron emission tomography (PET) are complimentary or 
alternative imaging modalities in asserting the diagnosis of PVE after TAVR. ${ }^{[15,16]}$ Antibiotic therapy without surgery in PVE is usually ineffective, especially when caused by a virulent pathogen or if complications develop. The majority of the cases of PVE after TAVR have an indication for SVR. However, the rate of surgical intervention in this population is close to $15 \% .^{[6,8,9]}$ The lower rate of intervention could be explained by higher risk profile, refusal of the patient, or contraindication to surgery due to complication from PVE. The in-hospital and 1-year follow up mortality rate is $40 \%$ and $60 \%$, respectively ${ }^{[6,9,12]}$ which seems to be in concordance with the mortality rate of PVE in the past decades. Multiple measures can be taken to prevent PVE such as engaging in periprocedural aseptic techniques and administering antibiotic prophylaxis during the procedure, or before dental procedures or urologic manipulations in pa-

\section{REFERENCES}

[1] Leon MB, Smith CR, Mack MJ, et al. Transcatheter aortic-valve implantation for aortic stenosis in patients who cannot undergo surgery. N Engl J Med. 2010; 363(17): 1597-607. PMid:20961243 https://doi.org/10.1056/NEJMoa1008232

[2] Smith CR, Leon MB, Mack MJ, et al. Transcatheter versus surgical aortic-valve replacement in high-risk patients. N Engl J Med. 2011; 364(23): 2187-98. PMid:21639811 https ://doi.org/10.1056/ NEJMoa1103510

[3] Leon MB, Smith CR, Mack M, et al. Transcatheter or Surgical AorticValve Replacement in Intermediate-Risk Patients. N Engl J Med 2016; 374(17): 1609-20. PMid:27040324 https ://doi.org/10.1 056/NEJMoa1514616

[4] van Kesteren F, Wiegerinck EMA, Rizzoet S, et al. Autopsy after transcatheter aortic valve implantation. Virchows Arch; 2017. PMid:28130699 https ://doi .org/10.1007/s00428-017-207 6-4

[5] Cahill TJ, Baddour LM, Habib HG, et al. Challenges in Infective Endocarditis. J Am Coll Cardiol. 2017; 69(3): 325-44. PMid:28104075 https://doi.org/10.1016/j.jacc.2016.10.066

[6] Amat-Santos IJ, Ribeiro HB, Urena M, et al. Prosthetic valve endocarditis after transcatheter valve replacement: a systematic review. JACC Cardiovasc Interv. 2015; 8(2): 334-46. PMid:25700757 https ://doi.org/10.1016/j.jcin.2014.09.013

[7] Latib A, Naim C, De Bonis M, et al. TAVR-associated prosthetic valve infective endocarditis: results of a large, multicenter registry. J Am Coll Cardiol. 2014; 64(20): 2176-8. PMid:25457406 https://doi.org/10.1016/j.jacc. 2014.09.021

[8] Regueiro A, Linke A, Latib A, et al. Association Between Transcatheter Aortic Valve Replacement and Subsequent Infective Endocarditis and In-Hospital Death. JAMA. 2016; 316(10): 1083-92. PMid:27623462 https ://doi.org/10.1001/jama.2016.1234 7

[9] Amat-Santos IJ, Messika-Zeitoun D, Eltchaninoff H, et al. Infective endocarditis after transcatheter aortic valve implantation: results from a large multicenter registry. Circulation. 2015; 131(18): 156674. PMid:25753535 https://doi .org/10.1161/CIRCULATIONA tients who received TAVR. ${ }^{[17]}$ Amoxicillin or ampicillin is usually sufficient. However, if there is suspicious for staphylococcus, antibiotics should be broaden based on oxacillin sensitivity. ${ }^{[18]}$

\section{Conclusion}

PVE after TAVR is a rare but deadly complication. Fever and heart failure are the most common presenting symptoms. Enterococcus and Staphylococcus are the most common pathogen identified in PVE after TAVR. TTE and CCT can be helpful to assess the complications after PVE. Surgery is indicated in most of the cases, as long as it can be performed safely. Aseptic technique and appropriate antibiotics prophylaxis decrease the risk of PVE.

\section{CONFlicts OF InTEREST Disclosure}

The authors have no competing interests to declare.
[10] Olsen NT, De Backer O, Thyregod HGH, et al. Prosthetic valve endocarditis after transcatheter aortic valve implantation. Circ Cardiovasc Interv. 2015; 8(4). PMid:25873728 https ://doi .org/10.1161/ CIRCINTERVENTIONS.114.001939

[11] Mylotte D, Andalib A, Thériault-Lauzier P, et al. Transcatheter heart valve failure: a systematic review. Eur Heart J. 2015; 36(21): 1306-27. PMid:25265974 https://doi.org/10.1093/eurheartj/ehu3 88

[12] Loverix L, Juvonen T, Biancari F. Prosthetic endocarditis after transcatheter aortic valve implantation: pooled individual patient outcome. Int J Cardiol. 2015; 178: 67-8. PMid:25464221 https: //doi.org/10.1016/j.ijcard.2014.10.136

[13] Wong DR, Boone RH, Thompson CR, et al. Mitral valve injury late after transcatheter aortic valve implantation. J Thorac Cardiovasc Surg. 2009; 137(6): 1547-9. PMid:19464478 https://doi.org/ $10.1016 / j$.jtcvs .2008 .06 .018

[14] Eisen A, Shapira Y, Sagie A, et al. Infective endocarditis in the transcatheter aortic valve replacement era: comprehensive review of a rare complication. Clin Cardiol. 2012; 35(11): E1-5. PMid:22990884 https://doi.org/10.1002/clc.22052

[15] Lane AB, Cahill MS, Letizia AG, et al. Multimodality imaging of multivalvular endocarditis after transcatheter aortic valve replacement. J Cardiovasc Comput Tomogr. 2015; 9(1): 68-70. PMid:25740417 https://doi.org/10.1016/j.jcct.2014.11 .002

[16] Sokalskis V, Muraru D, Fraccaro C, et al. Echocardiographic followup after transcatheter aortic valve replacement. Echocardiography; 2017. PMid:28052455 https://doi.org/10.1111/echo. 13443

[17] Loh PH, Bundgaard H, Sondergaard L. Infective endocarditis following transcatheter aortic valve replacement: diagnostic and management challenges. Catheter Cardiovasc Interv. 2013; 81(4): 623-7. PMid:22431450 https://doi.org/10.1002/ccd.24368

[18] Biteker FS, Mert KU, Mert GO, et al. Infective endocarditis prophylaxis in transcatheter aortic valve replacement. Int J Cardiol. 2014; 177(3): 1066. PMid:25465841 https://doi.org/10.1016/j.ij card.2014.11.009 